\title{
Aerosol-cloud drop concentration closure for clouds sampled during the International Consortium for Atmospheric Research on Transport and Transformation 2004 campaign
}

\author{
Christos Fountoukis, ${ }^{1}$ Athanasios Nenes, ${ }^{1,2}$ Nicholas Meskhidze, ${ }^{3,4}$ Roya Bahreini,, 6 \\ William C. Conant, ${ }^{5,7}$ Haflidi Jonsson, ${ }^{8}$ Shane Murphy, ${ }^{9}$ Armin Sorooshian, ${ }^{9}$ \\ Varuntida Varutbangkul, ${ }^{9}$ Fred Brechtel, ${ }^{5}$ Richard C. Flagan,,${ }^{5,10}$ and John H. Seinfeld,,${ }^{5,10}$ \\ Received 8 March 2006; revised 19 November 2006; accepted 21 February 2007; published 26 April 2007.
}

[1] This study analyzes 27 cumuliform and stratiform clouds sampled aboard the CIRPAS Twin Otter during the 2004 International Consortium for Atmospheric Research on Transport and Transformation (ICARTT) experiment. The data set was used to assess cloud droplet closure using (1) a detailed adiabatic cloud parcel model and (2) a state-of-the-art cloud droplet activation parameterization. A unique feature of the data set is the sampling of highly polluted clouds within the vicinity of power plant plumes. Remarkable closure was achieved (much less than the $20 \%$ measurement uncertainty) for both parcel model and parameterization. The highly variable aerosol did not complicate the cloud droplet closure, since the clouds had low maximum supersaturation and were not sensitive to aerosol variations (which took place at small particle sizes). The error in predicted cloud droplet concentration was mostly sensitive to updraft velocity. Optimal closure is obtained if the water vapor uptake coefficient is equal to 0.06 , but can range between 0.03 and 1.0 . The sensitivity of cloud droplet prediction error to changes in the uptake coefficient, organic solubility and surface tension depression suggest that organics exhibit limited solubility. These findings can serve as much needed constraints in modeling of aerosol-cloud interactions in the North America; future in situ studies will determine the robustness of our findings.

Citation: Fountoukis, C., et al. (2007), Aerosol-cloud drop concentration closure for clouds sampled during the International Consortium for Atmospheric Research on Transport and Transformation 2004 campaign, J. Geophys. Res., 112, D10S30, doi:10.1029/2006JD007272.

\section{Introduction}

[2] Most of the uncertainty in anthropogenic climate change is associated with aerosol-cloud interactions [Lohmann and Feichter, 2004; Andreae et al., 2005].

\footnotetext{
${ }^{1}$ School of Chemical and Biomolecular Engineering, Georgia Institute of Technology, Atlanta, Georgia, USA.

${ }^{2}$ Also at School of Earth and Atmospheric Sciences, Georgia Institute of Technology, Atlanta, Georgia, USA.

${ }^{3}$ School of Earth and Atmospheric Sciences, Georgia Institute of Technology, Atlanta, Georgia, USA.

${ }^{4}$ Now at School of Marine, Earth, and Atmospheric Sciences, North Carolina State University, Raleigh, North Carolina, USA.

${ }^{5}$ Environmental Science and Engineering, California Institute of Technology, Pasadena, California, USA.

${ }^{6}$ Now at NOAA, Boulder, Colorado, USA.

${ }^{7}$ Now at Department of Atmospheric Sciences, University of Arizona, Tucson, Arizona, USA.

${ }^{8}$ Center for Interdisciplinary Remotely-Piloted Aircraft Studies, Naval Postgraduate School, Monterey, California, USA.

${ }^{9}$ Department of Chemical Engineering, California Institute of Technology, Pasadena, California, USA.

${ }^{10}$ Also at Department of Chemical Engineering, California Institute of Technology, Pasadena, California, USA.
}

Copyright 2007 by the American Geophysical Union. 0148-0227/07/2006JD007272
Explicitly resolving cloud formation, microphysical evolution and aerosol-precipitation interactions in Global Climate Models (GCMs) is a challenging computational task [Khairoutdinov et al., 2005; Randall et al., 2003]; parameterizations are used instead. In terms of predicting droplet number, empirical correlations are often used [e.g., Jones et al., 1994; Gultepe and Isaac, 1996; Boucher and Lohmann, 1995; Lohmann and Feichter, 1997; Kiehl et al., 2000; Menon et al., 2002; Brasseur and Roeckner, 2005], which relate an aerosol property (usually total number or mass) to cloud droplet number concentration, $N_{d}$. The data is usually obtained from observations. Although simple and easy to implement, correlations are subject to substantial uncertainty [Kiehl et al., 2000]. Prognostic parameterizations of aerosol-cloud interactions have also been developed [Lohmann et al., 1999, 2000; Ghan et al., 2001a, 2001b; Rotstayn and Penner, 2001; Peng et al., 2002; Nenes and Seinfeld, 2003; Fountoukis and Nenes, 2005] in which $N_{d}$ is calculated using cloud-scale updraft velocity, aerosol size distribution and composition. These approaches are based on the "parcel" concept of 1-D Lagrangian numerical cloud models [e.g., Jensen and Charlson, 1984; Considine and Curry, 1998; Nenes et al., 2001]. Although inherently 

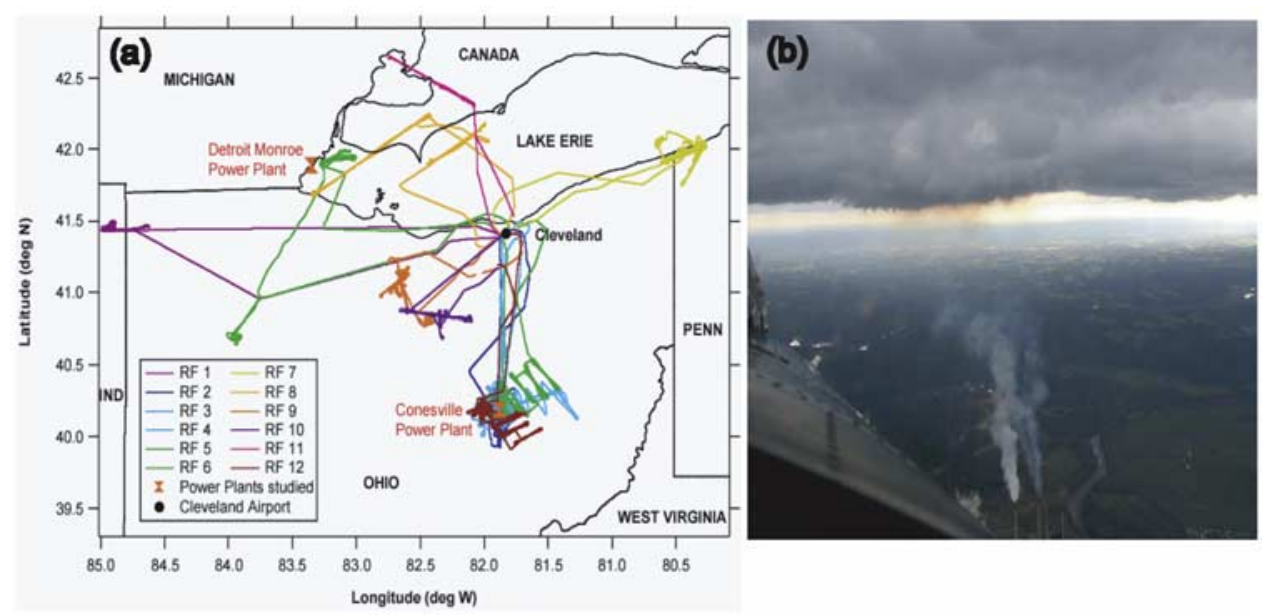

Figure 1. (a) Map of the 12 Twin Otter research flight tracks during ICARTT. (b) Photograph of Conesville power plant plume affecting cloud depth (flight IC3; 6 August 2004).

better than correlations, prognostic parameterizations are still subject to uncertainties in the subgrid (i.e., cloud-scale) updraft velocity [e.g., Menon et al., 2002], aerosol size distribution and composition [e.g., Rissman et al., 2004], aerosol "chemical" effects and changes in droplet growth kinetics [e.g., Nenes et al., 2002].

[3] The ultimate test for prognostic parameterizations and cloud models is the comparison of their predictions against comprehensive in situ data. When done for cloud droplet number, this procedure is termed "cloud droplet closure study," in which a discrepancy between $N_{d}$ predicted by models and measured in situ is usually determined. Hallberg et al. [1997] report $\sim 50 \%$ disagreement between predicted and observed $N_{d}$ for continental stratocumulus clouds. Chuang et al. [2000] studied marine and continental stratus clouds sampled during the second Aerosol Characterization Experiment (ACE-2) and found a large discrepancy (about a factor of 3 ) between predictions and observations for updraft velocity range expected for stratocumulus clouds. Snider and Brenguier [2000] and Snider et al. [2003] found up to 50\% discrepancy between predicted and measured droplet concentrations for ACE-2 and marine stratocumulus clouds. Part of this discrepancy was attributed to the usage of groundbased observations in the closure. Conant et al. [2004] achieved remarkable closure, to within $15 \%$, for cumulus clouds of marine and continental origin sampled during the NASA Cirrus Regional Study of Tropical Anvils and Cirrus Layers-Florida Area Cirrus Experiment (CRYSTALFACE). Meskhidze et al. [2005] also found excellent agreement between predicted and measured $N_{d}(\sim 30 \%)$ for the stratiform cloud data gathered during Coastal Stratocumulus Imposed Perturbation Experiment (CSTRIPE, Monterey, California, July 2003). In general, cloud droplet closure has been successful for clouds formed in clean air masses, and to a lesser degree for polluted clouds. It is however unclear if the latter results from limitations in the observations or in the theory used for predicting cloud droplet number.

[4] In this study we assess aerosol-cloud drop number closure using (1) a detailed cloud parcel model [Nenes et al., 2001] and (2) the parameterization of Nenes and Seinfeld [2003] with recent extensions by Fountoukis and
Nenes [2005] (hereinafter referred to as "modified NS" parameterization). The observations used in this study were collected on board the Center for Interdisciplinary Remotely Piloted Aircraft Studies (CIRPAS) Twin Otter aircraft (http://www.cirpas.org) during the NASA International Consortium for Atmospheric Research on Transport and Transformation experiment (ICARTT). A unique feature of this data set is the sampling of highly polluted cloudy air within the vicinity of power plant plumes. Closure with the parcel model tests our predictive understanding of cloud droplet formation under extremely polluted conditions, while using the parameterization assesses its performance and quantifies the uncertainty arising from its simplified physics.

\section{In Situ Observation Platform and Analysis Tools}

[5] During ICARTT, the Twin Otter realized twelve research flights in the vicinity of Cleveland and Detroit (Figure 1), several of which sampled cumuliform and stratiform clouds. Seven flights are considered in this study. The cloud sampling strategy involves several under-cloud "passes" to characterize the aerosol size distribution and chemical composition, followed by in-cloud "legs" to sample the cloud microphysics, chemistry and turbulence.

\subsection{Description of Airborne Platform}

[6] Table 1 summarizes the instruments and measured quantities aboard the CIRPAS Twin Otter aircraft. A Dual Automatic Classifier Aerosol Detector (DACAD [Wang et al., 2003]) was used to measure dry aerosol size between 10 and $800 \mathrm{~nm}$. The DACAD consists of two scanning Differential Mobility Analyzers (DMAs) operating in parallel, one at a "dry" relative humidity (RH) less than $20 \%$, and another at a "humid" RH of $\sim 75 \%$. From the dry-wet size distributions, the size-resolved hygroscopicity is obtained. Aerosol chemical composition (sulfate, nitrate, ammonium and organics) was measured in real time by an Aerodyne Aerosol Mass Spectrometer (AMS [Bahreini et al., 2003; Jayne et al., 2000]). Concurrently, aerosol inorganics $\left(\mathrm{NO}_{3}^{-}, \mathrm{SO}_{4}^{2-}, \mathrm{NH}_{4}^{+}\right)$and some organics (oxalate) 
were measured with a Particle-into-Liquid Sampler (PILS [Sorooshian et al., 2006a]). Updraft velocities were obtained from a five-hole turbulence probe, a Pitot-static pressure tube, a C-MIGITS GPS/INS Tactical System, GPS/inertial navigational system (INS), and the Novatel GPS system.

[7] Droplet number concentrations were measured with a Cloud and Aerosol Spectrometer (CAS) optical probe [Baumgardner et al., 2001], and the Forward Scattering Spectrometer Probe (FSSP [Brenguier et al., 1998; Jaenicke and Hanusch, 1993]). The FSSP measures droplets ranging from 1.5 to $37 \mu \mathrm{m}$ diameter. As with any optical counter, the FSSP is subject to numerous uncertainties such as variations of the size calibration and of the instrument sampling section, nonuniformity in light intensity of the laser beam, probe dead time and coincidence errors [Baumgardner and Spowart, 1990; Brenguier, 1989]. The FSSP is most accurate for measurements of $N_{d}$ below $200 \mathrm{~cm}^{-3}$ [Burnet and Brenguier, 2002]. At high droplet concentrations, $N_{d}$ can be noticeably underestimated when measured with the Fast-FSSP [Burnet and Brenguier, 2002]. The CAS measures droplet sizes from 0.4 to $50 \mu \mathrm{m}$ in 20 size bins using a measurement principle similar to that of the FSSP, but improved electronics relaxes the requirement for dead time and coincidence corrections [Burnet and Brenguier, 2002]. A Passive Cavity Aerosol Spectrometer Probe (PCASP) was also flown, which is an optical probe that measures particles between 100 and $2500 \mathrm{~nm}$.

\subsection{Cloud Parcel Model}

[8] The numerical cloud parcel model used in this study [Nenes et al., 2001, 2002] simulates the dynamical balance between water vapor availability from cooling of an ascending air parcel and water vapor depletion from condensation onto a growing droplet population. The model has successfully been used to assess cloud droplet closure in cumulus during CRYSTAL-FACE [Conant et al., 2004] and has been used in numerous model assessments of aerosol-cloud interactions [e.g., Nenes et al., 2002; Rissman et al., 2004; Lance et al., 2004]. The model predicts cloud droplet number concentration and size distribution using as input the cloud updraft velocity, aerosol size distribution and chemical composition. "Chemical effects," such as surface tension depression [Shulman et al., 1996; Facchini et al., 1999], partial solubility or the presence of film-forming compounds [Feingold and Chuang, 2002; Nenes et al., 2002; Rissman et al., 2004; Lance et al., 2004] can also be easily considered; their effect on droplet closure will be assessed through sensitivity analysis.

\subsection{Droplet Formation Parameterization}

[9] The modified NS parameterization [Fountoukis and Nenes, 2005] is one of the most comprehensive, robust and flexible formulations available for global models. The calculation of droplet number is based on the computation of maximum supersaturation, $s_{\max }$, within an ascending air parcel framework. The parameterization provides a computationally inexpensive algorithm for computing droplet number and size distribution and can treat externally mixed aerosol subject to complex chemical effects (e.g., surface tension effects, partial solubility, changes in water vapor uptake). The parameterization's excellent performance has been evaluated with detailed numerical cloud parcel model 
Table 2. ICARTT Cloud Characteristics for the Flights Considered in This Study

\begin{tabular}{|c|c|c|c|c|c|c|c|c|}
\hline $\begin{array}{l}\text { Flight (Cloud) } \\
\text { Number } \\
\end{array}$ & $\begin{array}{l}\text { Flight } \\
\text { Date }\end{array}$ & $w_{+}, \mathrm{ms}^{-1}$ & $\sigma_{+}, \mathrm{ms}^{-1}$ & $\begin{array}{c}\text { Observed } N_{d}, \mathrm{~cm}^{-3} \\
( \pm \text { st.dev\% })\end{array}$ & $\begin{array}{c}\text { Predicted } N_{d}, \mathrm{~cm}^{-3} \\
\text { Parcel Model } \\
\text { (Parameterization) } \\
\end{array}$ & $\begin{array}{l}\text { Originating } \\
\text { Air Mass }{ }^{\mathrm{a}} \\
\text { (Cloud Type) } \\
\end{array}$ & $\begin{array}{c}\text { Mission } \\
\text { Description }\end{array}$ & $\begin{array}{c}\text { Wind } \\
\text { Direction }\end{array}$ \\
\hline IC3 (1) & 6 Aug & 1.67 & 0.868 & $1086(15.9)$ & $1046(1066)$ & clean (cumulus) & Conesville $\mathrm{PP}^{\mathrm{b}}$ & $\mathrm{N}$ \\
\hline IC3 (2) & 6 Aug & 0.39 & 1.732 & $354(45.6)$ & $321(356)$ & clean (stratocu) & Conesville $\mathrm{PP}^{\mathrm{b}}$ & $\mathrm{N}$ \\
\hline IC3 (3) & 6 Aug & 1.89 & 0.750 & $825(44.5)$ & 1109 (1116) & clean (cumulus) & Conesville $\mathrm{PP}^{\mathrm{b}}$ & $\mathrm{N}$ \\
\hline IC3 (4) & $6 \mathrm{Aug}$ & 1.18 & 0.619 & $828(27.0)$ & $980(943)$ & clean (cumulus) & Conesville $\mathrm{PP}^{\mathrm{b}}$ & $\mathrm{N}$ \\
\hline IC5 (1) & 9 Aug & 0.69 & 0.407 & $1293(9)$ & $1607(1420)$ & polluted (cumulus) & Conesville $\mathrm{PP}^{\mathrm{b}}$ & W-SW \\
\hline IC5 (2) & 9 Aug & 0.28 & 0.209 & $1160(17)$ & $1147(1224)$ & polluted (stratocu) & Conesville $\mathrm{PP}^{\mathrm{b}}$ & W-SW \\
\hline IC5 (3) & 9 Aug & 0.59 & 0.528 & $1045(37.8)$ & $1223(1281)$ & polluted (cumulus) & Conesville $\mathrm{PP}^{\mathrm{b}}$ & W-SW \\
\hline IC6 (1) & 10 Aug & 0.69 & 0.430 & $695(14.7)$ & $744(813)$ & polluted (stratocu) & Monroe $\mathrm{PP}^{\mathrm{b}}$ & W-SW \\
\hline IC6 (2) & 10 Aug & 0.35 & 0.283 & $415(50.1)$ & $508(577)$ & polluted (stratus) & Monroe $\mathrm{PP}^{\mathrm{b}}$ & NW-SW \\
\hline IC6 (3) & 10 Aug & 0.44 & 0.303 & $668(28.4)$ & $555(636)$ & polluted (stratus) & Monroe $\mathrm{PP}^{\mathrm{b}}$ & NW-SW \\
\hline IC6 (4) & 10 Aug & 0.69 & 0.375 & $808(25.6)$ & $745(809)$ & polluted (stratocu) & Monroe $\mathrm{PP}^{\mathrm{b}}$ & NW-SW \\
\hline IC6 (5) & 10 Aug & 0.57 & 0.477 & $700(47.8)$ & $649(730)$ & polluted (stratocu) & Monroe $\mathrm{PP}^{\mathrm{b}}$ & NW-SW \\
\hline IC6 (6) & 10 Aug & 1.07 & 0.819 & $1075(15.7)$ & $1008(1073)$ & polluted (stratocu) & Monroe $\mathrm{PP}^{\mathrm{b}}$ & NW-SW \\
\hline IC9 (1) & 16 Aug & 0.59 & 0.360 & $1012(31.9)$ & $1000(1089)$ & clean $($ stratocu) & SW of Cleveland & NW-SW \\
\hline IC9 (2) & 16 Aug & 0.17 & 0.131 & $540(36)$ & $487(455)$ & clean (stratus) & SW of Cleveland & NE-N \\
\hline IC9 (3) & 16 Aug & 0.15 & 0.170 & $524(48.5)$ & $413(392)$ & clean (stratus) & SW of Cleveland & NE-N \\
\hline IC9 (4) & 16 Aug & 0.72 & 0.727 & $1229(8.7)$ & $1507(1384)$ & clean (stratocu) & SW of Cleveland & NE-N \\
\hline IC10 (1) & 17 Aug & 0.69 & 0.401 & $1258(6)$ & 1306 (1367) & polluted (cumulus) & SW of Cleveland & NE-N \\
\hline IC10 (2) & 17 Aug & 0.47 & 0.228 & $1040(19.6)$ & $1309(1060)$ & polluted (stratocu) & SW of Cleveland & S-SW \\
\hline IC10 (3) & 17 Aug & 0.17 & 0.212 & $811(20.4)$ & $718(495)$ & polluted (stratocu) & SW of Cleveland & S-SW \\
\hline IC11 (1) & 18 Aug & 0.35 & 0.313 & $963(14.1)$ & $803(780)$ & polluted (stratocu) & SW of Ontario & S-SW \\
\hline IC11 (2) & 18 Aug & 0.54 & 0.621 & $954(32.1)$ & $1056(1054)$ & polluted (stratocu) & SW of Ontario & S-SW \\
\hline IC11 (3) & 18 Aug & 0.62 & 0.428 & $965(13.1)$ & 1145 (1153) & polluted (stratocu) & SW of Ontario & S-SW \\
\hline IC11 (4) & 18 Aug & 0.56 & 0.239 & $1141(18.6)$ & $1060(1080)$ & polluted (stratocu) & SW of Ontario & S-SW \\
\hline IC12 (1) & $21 \mathrm{Aug}$ & 0.55 & 0.823 & $1314(24.3)$ & $1269(1265)$ & polluted (cumulus) & Conesville $\mathrm{PP}^{\mathrm{b}}$ & S-SW \\
\hline IC12 (2) & 21 Aug & 0.38 & 0.250 & $1016(32.1)$ & $783(766)$ & polluted (stratocu) & Conesville $\mathrm{PP}^{\mathrm{b}}$ & NW-SW \\
\hline IC12 (3) & $21 \mathrm{Aug}$ & 0.12 & 0.134 & 322 (11.1) & $287(296)$ & polluted (stratocu) & Conesville $\mathrm{PP}^{\mathrm{b}}$ & $\mathrm{N}$ \\
\hline
\end{tabular}

aSee section 3.1 for characteristics of air mass types.

bead "PP" as "power plant."

simulations [Nenes and Seinfeld, 2003; Fountoukis and Nenes, 2005] and in situ data for cumuliform and stratiform clouds of marine and continental origin [Meskhidze et al., 2005]. Formulations for sectional [Nenes and Seinfeld, 2003] or lognormal [Fountoukis and Nenes, 2005] aerosol have been developed. The latter (lognormal) formulation is used in this study.

\section{Observations and Analysis}

\subsection{Description of Research Flights}

[10] Seven flights are analyzed in this study, in which 27 clouds are profiled (Table 2). The clouds formed downwind of power plants, Cleveland and Detroit. Three research flights (IC3,5 and 12) sampled clouds downwind of the Conesville power plant (Figure 1a), one flight (IC6) sampled clouds downwind of the Monroe power plant (Figure 1a), two flights (IC 9,10) sampled clouds southwest of Cleveland (Figure 1a) and one flight (IC11) sampled clouds southwest of Ontario (Figure 1a). Flight IC3 was the first to probe the Conesville power plant plume; its visible impact on local clouds (Figure 1b) motivated two more research flights (IC5 and 12) that fully characterized the plume and its influence on clouds. Backward Lagrangian trajectory analysis computed from the NOAA-HYSPLIT model (http://www.arl.noaa.gov/ready/hysplit4.html) suggests that during flights IC3 and IC9, the air mass sampled was transported by northerlies (Figure 2a). The air sampled in all other flights originated in the boundary layer and was transported by westerly winds (Figure 2b). Prevailing wind directions, cloud types and other characteristics for each cloud case are given in Table 2.

\subsection{Cloud Droplet Number and Updraft Velocity Measurements}

[11] The observed cloud droplet spectra are carefully screened to eliminate biases in $N_{d}$. Dilution biases are avoided by considering only measurements with effective droplet diameter greater than $2.4 \mu \mathrm{m}$ and geometric standard deviation less than 1.5 [Conant et al., 2004]. A lack of a drizzle mode (liquid water) present, i.e., negligible concentrations of droplets larger than $30 \mu \mathrm{m}$ (typically $0-0.2 \mathrm{~cm}^{-3}$ ) suggest that collision-coalescence and drizzle formation were not important for the clouds sampled. Particles below $1 \mu \mathrm{m}$ are either evaporating or unactivated haze and not counted as droplets.

[12] For flights before 13 August, the CAS suffered from a saturation bias for concentrations above $1500 \mathrm{~cm}^{-3}$. About 3\% of the data set was subject to this bias and was disregarded from this study. The CAS was also found to overcount droplets smaller than $6 \mu \mathrm{m}$ but reliably counted droplet larger than $6 \mu \mathrm{m}$. This problem is addressed by disregarding the 1-6 $\mu \mathrm{m}$ CAS data and replacing them with FSSP data corrected for dead time and coincidence errors [Burnet and Brenguier, 2002]. Droplet concentration uncertainty was assessed by comparing FSSP and CAS concentrations in the $6-10 \mu \mathrm{m}$ range; the former was to be about $40 \%$ lower than the latter. As all known sources of bias are accounted for in the FSSP correction, we assume that the difference between the two probes $(40 \%)$ expresses an unbiased uncertainty $( \pm 20 \%)$ in observed droplet concentration for the whole data set and droplet size range.

[13] The observed cloud droplet concentrations for each flight are presented in Table 2. Average $N_{d}$ varied from $320 \mathrm{~cm}^{-3}$ to $1300 \mathrm{~cm}^{-3}$ and as expected, correlated with 
a NOAA HYSPLIT MODEL

Backward trajectories ending at 19 UTC 06 Aug 04 CDC1 Meteorological Data

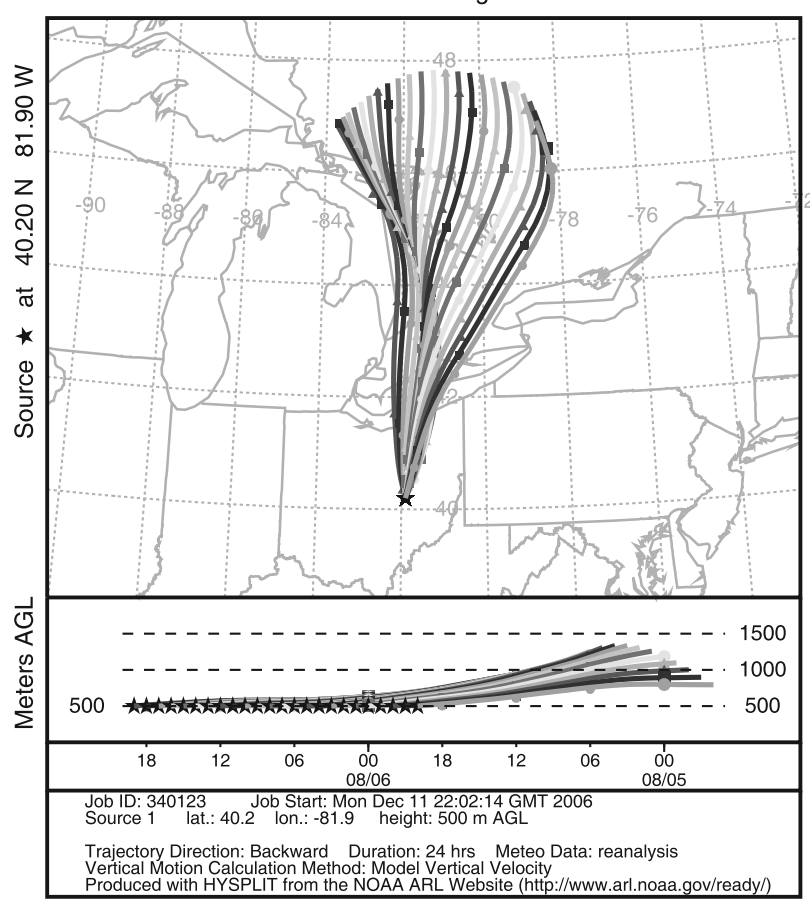

b NOAA HYSPLIT MODEL Backward trajectories ending at 21 UTC 10 Aug 04 CDC1 Meteorological Data

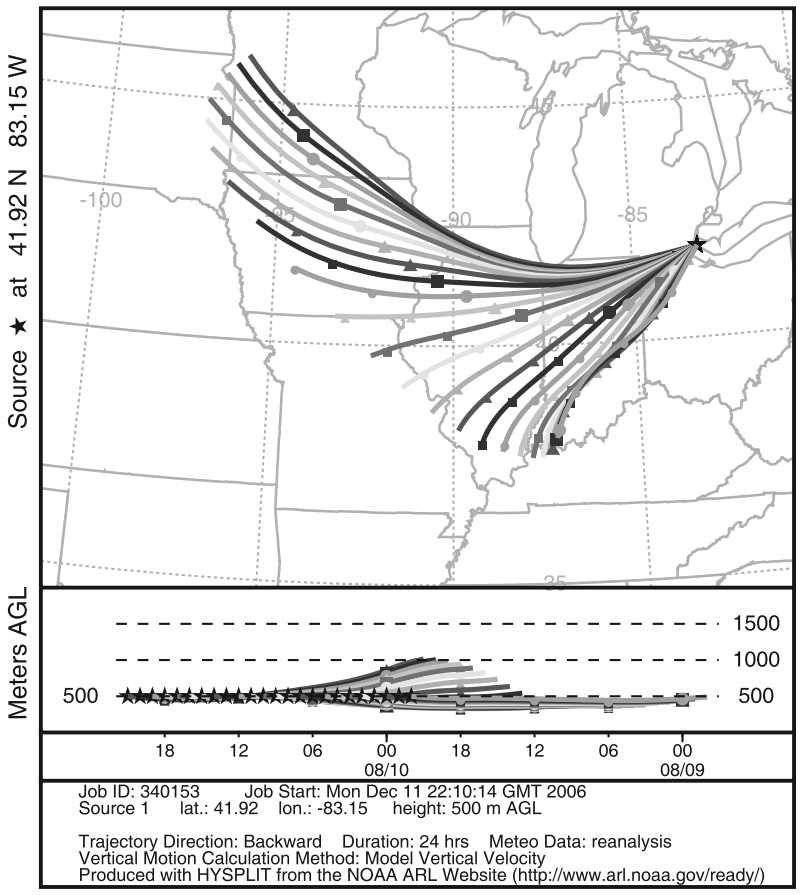

Figure 2. HYSPLIT backward trajectory analysis for (a) flight IC3 and (b) flight IC6.

cloud updraft velocity, $w$; clouds with $N_{d}>1000 \mathrm{~cm}^{-3}$ typically had $w>1 \mathrm{~m} \mathrm{~s}^{-1}, N_{d} \sim 500-1000$ for $w \sim 0.5 \mathrm{~m} \mathrm{~s}^{-1}$ and $N_{d} \sim 300-500$ for $w \sim 0.25 \mathrm{~m} \mathrm{~s}^{-1}$. High droplet concentration (even for clouds with low updraft velocity) is indicative of the high aerosol loading in almost all clouds profiled.

[14] As expected, updraft velocity varied significantly in each cloud (even at cloud base); we chose to fit observations to a mass-flux-weighted Gaussian probability density function (pdf), as discussed by Meskhidze et al. [2005] and Conant et al. [2004]. Aircraft turns were eliminated from our analysis and the pdf in the measurements were shifted to have a mean of zero (consistent with the assumption of a slowly evolving boundary layer). Table 2 shows the values of average updraft velocity (closest to cloud base) and its standard deviation. Average cloud updraft velocity (at cloud base), $w_{+}$, varied between $0.12( \pm 0.13)$ and $1.89( \pm 0.73)$ $\mathrm{m} \mathrm{s}^{-1} \cdot w_{+}$and its standard deviation, $\sigma_{+}$, were highly correlated (Figure 3); typical of stratocumulus clouds, $\sigma_{+}$is significant and comparable to the mean updraft velocity.

\subsection{Aerosol Size Distribution and Composition}

[15] Flight legs were first conducted below cloud base to characterize aerosol composition and size distribution, followed by constant-altitude transects through the cloud; a final pass was done at the cloud top (at 300-1000 m). The vertical profiles and horizontal transects are used to deduce cloud spatial extent and height. The under-cloud aerosol size distributions are averaged and fit to three (or four) lognormal modes (depending on the observations) using least squares minimization. Average total aerosol concentration ranged from $4200 \mathrm{~cm}^{-3}$ to $13300 \mathrm{~cm}^{-3}$; the distribution information for each cloud case is summarized in Table 3.
[16] Whenever available (flights IC3, IC5, IC6), AMS measurements were used to describe the dry aerosol composition. The AMS always detected significant amounts of organics, constituting $35-85 \%$ of the total aerosol mass. Highest organic mass fractions were observed outside of power plant plumes (Table 3). The ammonium-sulfate molar ratio obtained both by the PILS and the AMS was larger than 2 for most flights (ranging from 2.0 to 3.7), except for IC5, where the ratio was 1.75 . This suggests that the aerosol was

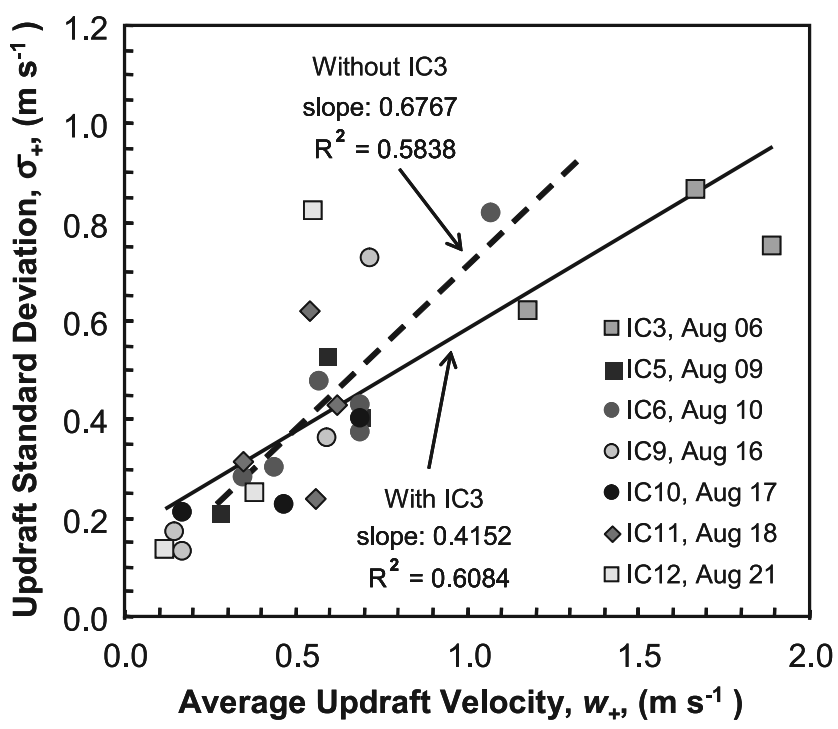

Figure 3. Correlation between average cloud base updraft velocity and velocity standard deviation. All clouds listed in Table 2 are used. 
Table 3. Aerosol Size Distribution and Chemical Composition for ICARTT Clouds

\begin{tabular}{|c|c|c|c|c|c|}
\hline$\underline{\text { Flight Number (Date) }}$ & $\begin{array}{c}\text { Aerosol } \\
\text { Mode }\end{array}$ & $\begin{array}{c}\text { Modal } D_{p g}, \\
\mu \mathrm{m}\end{array}$ & Modal $\sigma$ & $\begin{array}{l}\text { Modal } N_{a p}, \\
\mathrm{~cm}^{-3}\end{array}$ & $\begin{array}{c}\left(\mathrm{NH}_{4}\right)_{2} \mathrm{SO}_{4} \text { Mass } \\
\text { Fraction, \% } \\
\end{array}$ \\
\hline IC3 $(8 / 6 / 2004)$ & nucleation & 0.014 & 1.253 & 6667 & 40 \\
\hline IC3 $(8 / 6 / 2004)$ & accumulation & 0.024 & 1.222 & 2630 & 40 \\
\hline IC3 $(8 / 6 / 2004)$ & coarse & 0.064 & 1.720 & 1541 & 40 \\
\hline IC5-a (8/9/2004) & nucleation & 0.027 & 1.477 & 2813 & 61 \\
\hline IC5-a $(8 / 9 / 2004)$ & accumulation & 0.112 & 1.638 & 3353 & 61 \\
\hline IC5-a (8/9/2004) & coarse & 0.253 & 1.176 & 530 & 61 \\
\hline IC5-b (8/9/2004) & nucleation & 0.030 & 1.330 & 2949 & 61 \\
\hline IC5-b (8/9/2004) & accumulation & 0.051 & 1.121 & 486 & 61 \\
\hline IC5-b (8/9/2004) & coarse & 0.124 & 1.712 & 3170 & 61 \\
\hline IC5-c $(8 / 9 / 2004)$ & nucleation & 0.013 & 1.066 & 163 & 66 \\
\hline IC5-c $(8 / 9 / 2004)$ & accumulation & 0.035 & 1.479 & 2578 & 66 \\
\hline IC5-c $(8 / 9 / 2004)$ & coarse & 0.138 & 1.708 & 2995 & 66 \\
\hline IC6-a (8/10/2004) & nucleation & 0.015 & 1.336 & 2287 & 65 \\
\hline IC6-a $(8 / 10 / 2004)$ & accumulation & 0.042 & 1.400 & 3856 & 65 \\
\hline IC6-a $(8 / 10 / 2004)$ & coarse & 0.141 & 1.663 & 652 & 65 \\
\hline IC6-b $(8 / 10 / 2004)$ & nucleation & 0.014 & 1.230 & 1881 & 65 \\
\hline IC6-b $(8 / 10 / 2004)$ & accumulation & 0.040 & 1.496 & 4381 & 65 \\
\hline IC6-b $(8 / 10 / 2004)$ & accumulation & 0.163 & 1.534 & 533 & 65 \\
\hline IC6-b $(8 / 10 / 2004)$ & coarse & 0.738 & 1.027 & 0.1 & 65 \\
\hline IC9-a (8/16/2004) & nucleation & 0.032 & 1.720 & 11890 & 15 \\
\hline IC9-a (8/16/2004) & accumulation & 0.128 & 1.380 & 1310 & 15 \\
\hline IC9-a (8/16/2004) & coarse & 0.274 & 1.150 & 420 & 15 \\
\hline IC9-b (8/16/2004) & nucleation & 0.051 & 1.438 & 8491 & 70 \\
\hline IC9-b (8/16/2004) & accumulation & 0.135 & 1.339 & 1365 & 70 \\
\hline IC9-b (8/16/2004) & coarse & 0.249 & 1.161 & 289 & 70 \\
\hline IC9-c (8/16/2004) & nucleation & 0.056 & 1.384 & 7959 & 50 \\
\hline IC9-c $(8 / 16 / 2004)$ & accumulation & 0.141 & 1.354 & 1300 & 50 \\
\hline IC9-c (8/16/2004) & coarse & 0.260 & 1.140 & 244 & 50 \\
\hline IC10-a (8/17/2004) & nucleation & 0.016 & 1.161 & 469 & 38 \\
\hline IC10-a $(8 / 17 / 2004)$ & accumulation & 0.037 & 1.360 & 4702 & 38 \\
\hline IC10-a (8/17/2004) & accumulation & 0.077 & 1.060 & 243 & 38 \\
\hline IC10-a (8/17/2004) & coarse & 0.143 & 1.581 & 1953 & 38 \\
\hline IC10-b (8/17/2004) & nucleation & 0.024 & 1.269 & 3577 & 38 \\
\hline IC10-b (8/17/2004) & accumulation & 0.042 & 1.123 & 355 & 38 \\
\hline IC10-b (8/17/2004) & coarse & 0.112 & 1.841 & 2393 & 38 \\
\hline IC11 (8/18/2004) & nucleation & 0.017 & 1.521 & 1322 & 15 \\
\hline IC11 (8/18/2004) & accumulation & 0.098 & 1.676 & 2339 & 15 \\
\hline IC11 (8/18/2004) & coarse & 0.237 & 1.289 & 587 & 15 \\
\hline IC12 (8/21/2004) & nucleation & 0.013 & 1.117 & 133 & 36 \\
\hline IC12 (8/21/2004) & accumulation & 0.096 & 1.296 & 206 & 36 \\
\hline IC12 (8/21/2004) & coarse & 0.082 & 1.728 & 4336 & 36 \\
\hline
\end{tabular}

neutralized in all flights except IC5. Lack of size-resolved composition precludes the detection of acidity changes throughout the aerosol distribution, but any gas phase ammonia (for all flights except IC5) would quickly condense and neutralize acidic particles formed from in-cloud production of sulfate. The PILS analysis showed small amounts of nitrate and oxalate, the latter being generated by in-cloud oxidation of organic precursors [Sorooshian et al., 2006b]. It is unclear whether particulate nitrate is associated with aerosol phase organics. When combined, nitrates and oxalate did not exceed $2 \%$ of the total (soluble + insoluble) aerosol mass and were excluded from our analysis; a small change in the soluble fraction would not significantly impact droplet concentrations [Rissman et al., 2004]. Table 3 presents the aerosol size distribution and composition for each cloud case considered in this study.

[17] Additional compositional insight (and its spatial variability) can be obtained from the DACAD; the hygroscopic growth factor (wet over dry aerosol diameter) during flight IC3 was $\sim 1.17$, (compared to 1.44 for pure ammonium sulfate at $77 \%$ relative humidity), characteristic of carbonaceous material with low sulfate content. Ageing of the plume downwind showed an increase in hygroscopicity, consistent with condensation of sulfates on the aerosol. The influence of the power plant plume could be detected for more than 20 miles downwind of the plant (Figure 4). Representative examples of measured and fitted size distributions are shown in Figure 5; the discrepancy for CCNrelevant size range (larger than $30 \mathrm{~nm}$ ) is generally small, less than $10 \%$.

\subsection{Cloud Droplet Closure: Parcel Model}

[18] The average updraft velocity, $w_{+}$, is used to compute $N_{d}$; this was shown by Meskhidze et al. [2005] to give optimal closure for cumulus and stratocumulus clouds. $w_{+}$is defined as, $w_{+}=\int_{0}^{\infty} w p(w) d w / \int_{0}^{\infty} p(w) d w$, where $p(w)$ is the vertical velocity probability density function (pdf). For a Gaussian pdf with standard deviation $\psi_{w}$ and zero average velocity, $p(w)=\frac{1}{(2 \pi)^{1 / 2} \psi_{w}} \exp \left\{-\frac{w^{2}}{2 \psi_{w}^{2}}\right\}$, and

$$
w_{+}=\frac{-\frac{\psi_{w}}{(2 \pi)^{1 / 2}} \int_{0}^{\infty} \exp (-x) d(-x)}{0.5}=\left(\frac{2}{\pi}\right)^{1 / 2} \psi_{w} \cong 0.8 \psi_{w}
$$




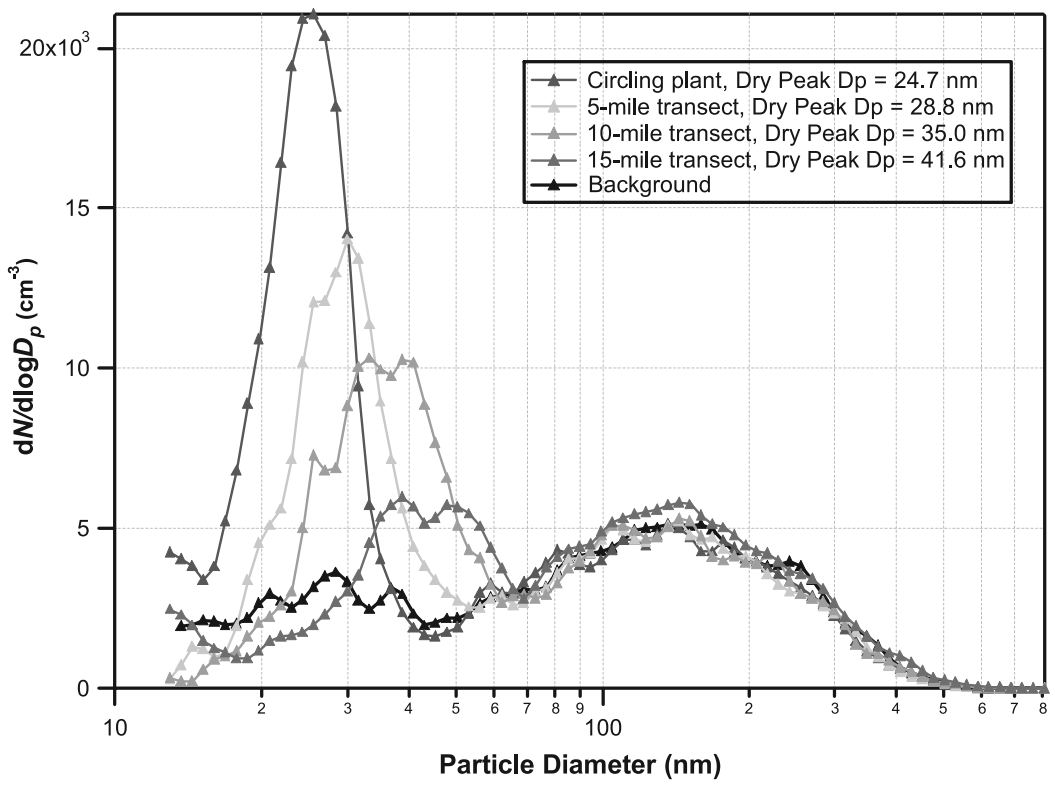

Figure 4. Dry aerosol size distributions for flight IC5 (Conesville power plant). Distributions are shown for plume transects downwind of the power plant.

$w_{+}$, as calculated from equation (1), is identical to the "characteristic" velocity found by Peng et al. [2005] used for assessing cloud droplet closure for stratocumulus clouds sampled in the North Atlantic Ocean. Equation (1) is also reflected in the updraft velocity observations (Figure 3); $\sigma_{+}$, which is roughly half of $\psi_{w}$, yields after substitution into equation (1) $\sigma_{+} \cong 0.63 w_{+}$, which is consistent with the slope of Figure 3.

[19] The under-cloud temperature, pressure and relative humidity describe the precloud thermodynamic state of the atmosphere and are used as initial conditions for the parcel model. Aerosol observations and cloud updraft velocity are obtained from Tables 2 and 3.

[20] It is assumed that the aerosol is internally mixed and composed of two compounds: ammonium sulfate (with density $\rho_{\text {sul }}=1760 \mathrm{~kg} \mathrm{~m}^{-3}$ ) and organic (with density $\rho_{\text {org }}=1500 \mathrm{~kg} \mathrm{~m}^{-3}$ ). The "organic" density is slightly larger than the $1200-1250 \mathrm{~kg} \mathrm{~m}^{-3}$ value of Turpin and Lim [2001] proposed for Los Angeles to account for ageing and the presence of some crustal species. For flights which AMS data were not available (i.e., IC9, IC10, IC11, IC12), the "insoluble" volume fraction, $V_{i n s}$, was inferred by subtracting the ammonium sulfate volume, $V_{\text {sul }}$, (obtained from PILS measurements) from the total aerosol volume, $V_{\text {total }}$ (obtained from size distribution measurements). The mass fraction of the insoluble material, $m_{\text {ins }}$, is then calculated as,

$$
m_{\text {ins }}=\frac{\rho_{\text {org }} V_{\text {ins }}}{\rho_{\text {sul }} V_{\text {sul }}+\rho_{\text {org }} V_{\text {ins }}}
$$

The assumption that only inorganics contribute soluble mass relevant for $\mathrm{CCN}$ activation appears to be reasonable in $\mathrm{CCN}$ closure studies conducted in North America [e.g., Medina et al., 2007; Broekhuizen et al., 2005]. Equation (2) assumes uniform composition with size; this can introduce a significant amount of uncertainty in predicting $\mathrm{CCN}$ concentrations [e.g., Medina et al., 2007; Broekhuizen et al., 2005]. The importance of both assumptions in cloud droplet number prediction is discussed in section 3.5.

[21] The mass water vapor uptake (condensation) coefficient, $a_{c}$, needed for computing the water vapor mass transfer coefficient [Fountoukis and Nenes, 2005] is currently subject to considerable uncertainty. Li et al. [2001] have shown that if uptake is controlled by the accommodation of water vapor molecules onto droplets, $a_{c}$ can range from 0.1 to 0.3 for pure water droplets, from 0.04 to 0.06 for aged atmospheric CCN [Shaw and Lamb, 1999; Pruppacher and Klett, 2000; Chuang, 2003; Conant et al., 2004], while a recent work suggests that it should be close to unity for dilute droplets and pure water [Laaksonen et al., 2004]. However, ambient CCN at the point of activation are concentrated solutions composed of electrolytes and (potentially) organic surfactants,

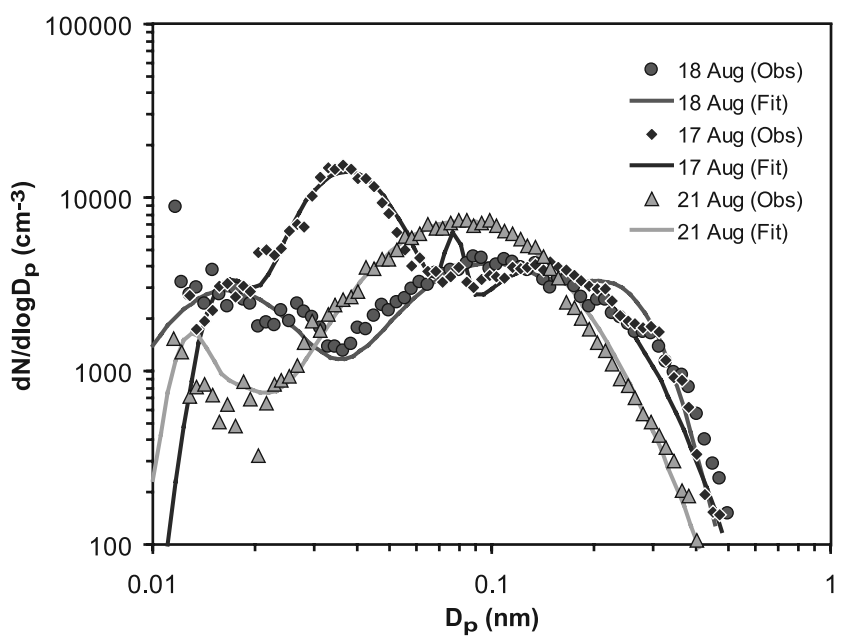

Figure 5. Examples of observed size distributions and corresponding lognormal fits. 


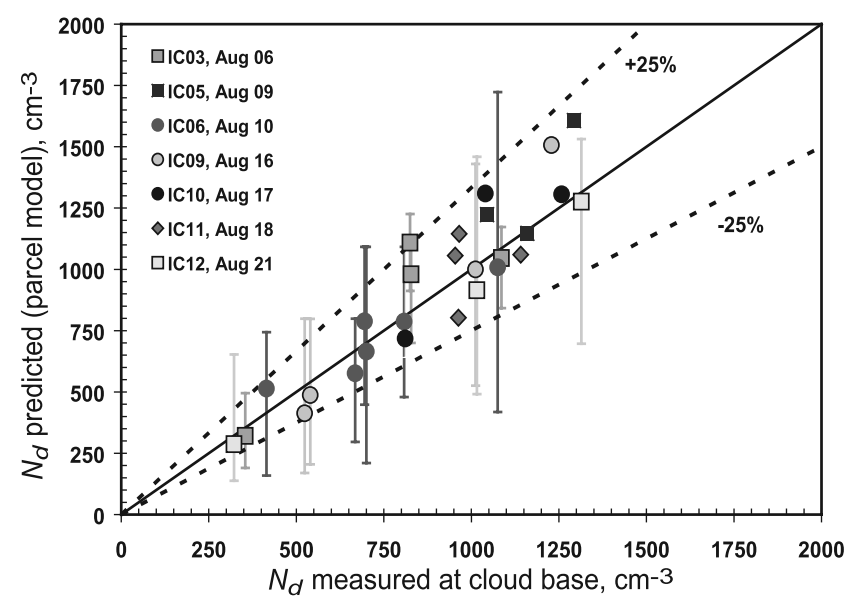

Figure 6. Cloud droplet number closure using the parcel model. The conditions for predicting $N_{d}$ are summarized in Tables 2 and 3.

which, together with other kinetic processes (e.g., solute dissolution [Asa-Awuku and Nenes, 2007]), can slow water uptake and growth kinetics; this would give an apparent uptake coefficient much less than unity (even if $a_{c}$ were unity). Because of this, and following the suggestions of Shaw and Lamb [1999] and Conant et al. [2004], we consider a "base case" value of $a_{c}$ equal to 0.06 . The data set (Tables 2 and 3) is used to determine a "best fit" value for $a_{c}$ and constrain its uncertainty (section 3.5).

[22] Figure 6 shows the cloud droplet number closure for all 27 clouds analyzed in this study. The parcel model predictions of $N_{d}$ are close to the 1:1 line of perfect agreement with observations. In most cases, predictions are within $25 \%$ of the observations (average error $3.0 \pm 15.4 \%$; average absolute error $12.8 \pm 8.7 \%$ ), which is considerably less than the estimated $N_{d}$ uncertainty of $\sim 20 \%$.

\subsection{Cloud Droplet Closure: Modified NS Parameterization}

[23] Evaluation of the modified NS parameterization is carried out via a closure study, using the procedure outlined in section 3.3. The results are shown in Figure 7; on average, the modified NS parameterization was found to reproduce observed $N_{d}$ with the same accuracy as the parcel model (average error $1.5 \pm 17.9 \%$; average absolute error $13.5 \pm 11.5 \%)$. There is no systematic bias between the modeled and the observed $N_{d}$. This is remarkable, given that highly polluted clouds formed from $\mathrm{CCN}$ containing large amounts of organics have long been considered a challenge for any parameterization and parcel model [e.g., Conant et al., 2004]. This study, combined with the work of Meskhidze et al. [2005] clearly show that the modified NS parameterization can accurately and robustly predict the process of cloud droplet activation and reliably be used in GCM assessments of the aerosol indirect effect.

\subsection{Sources of Uncertainty and Sensitivity Analyses}

[24] Despite the excellent closure, it is important to identify key contributors to $N_{d}$ error (defined as the difference between predicted and measured $N_{d}$ normalized to measured $N_{d}$ ). This is done by examining the correlation of $N_{d}$ error with key parameters affecting $N_{d}$, being (1) total aerosol number, (2) accumulation mode aerosol number, (3) average cloud base updraft velocity, (4) cloud base updraft velocity variance, (5) observed cloud droplet number, and (6) aerosol sulfate mass fraction. The first two parameters are used as a proxy for pollution. The next two parameters are used as a proxy for cloud dynamics, which strongly impact cloud droplet number and its sensitivity to "chemical effects" [e.g., Nenes et al., 2002; Rissman et al., 2004]. Sulfate mass fraction itself is a proxy for "chemical effects," as low sulfate is usually correlated with high organic content, which in turn may be water-soluble and contain surfactants. Finally, observed cloud droplet number is used to explore whether the $N_{d}$ observations are subject to some concentrationdependant bias (section 3.2). Table 4 presents the results of the correlation analysis. When the whole data set is considered, $N_{d}$ error only correlates significantly with $w_{+}$ $\left(\mathrm{R}^{2}\right.$ in Table 4 is for $\left.w_{+}<1 \mathrm{~m} \mathrm{~s}^{-1}\right)$ and its variance. There is practically no correlation of droplet error with $w_{+}$when it is above $1.0 \mathrm{~m} \mathrm{~s}^{-1}$ (roughly $50 \%$ of the data set). The correlation of error with updraft is stronger as the $w_{+}$ decreases; this is expected as vertical velocity uncertainty becomes substantial for low updrafts. Lack of droplet error correlation with chemical composition variations is consistent with Rissman et al. [2004], who show droplet number is most sensitive to variations in updraft velocity under conditions of low supersaturation (i.e., strong competition for water vapor from high aerosol concentration and low updraft velocity). When considering subsets of data, updraft velocity still correlates with droplet error (Table 4), more weakly $\left(\mathrm{R}^{2}=0.2\right)$ for power plant flights alone (IC3,5,6,12) and more strongly $\left(\mathrm{R}^{2}=0.5\right)$ for non-power-plant plume flights $(\mathrm{IC} 9,10,11)$. The strength of correlation is expected, as power plant clouds are more vigorous $\left(56 \%\right.$ have $w_{+}>1.0$, and only $6 \%$ with $\left.w_{+}<0.25\right)$, than non-power-plant clouds (55\% have $w_{+}>1.0$, and $27 \%$ with $w_{+}<0.25$ ).

[25] For power plant flights alone, droplet error also correlates with aerosol number. This is likely from the temporal averaging of the aerosol size distribution; an averaged distribution cannot account for the spatial heterogeneity of the aerosol (hence droplet number) in the vicinity of power plant plumes. Therefore droplet error does not arise

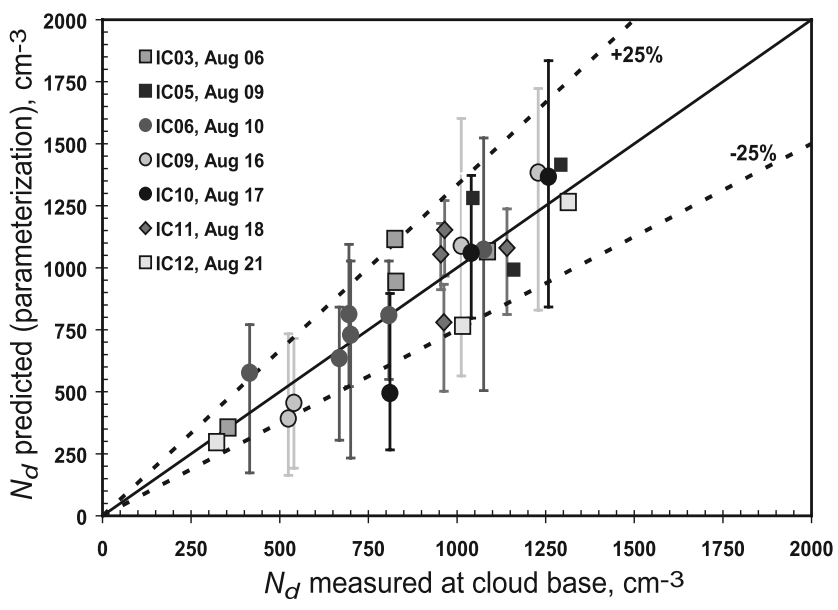

Figure 7. Same as Figure 3 but using the modified NS parameterization for predicting $N_{d}$. 
Table 4. Correlation of Droplet Number Error With Important Aerosol-Cloud Interaction Properties ${ }^{\mathrm{a}}$

\begin{tabular}{lccc}
\hline & \multicolumn{3}{c}{ Correlation Coefficient $\left(\mathrm{R}^{2}\right)$} \\
\cline { 2 - 4 } \multicolumn{1}{c}{ Observed Property } & Whole Data Set & Non-Power-Plant & Power Plant Only \\
\hline Total aerosol number & 0.002 & 0.018 & $\mathbf{0 . 1 1 1}$ \\
Accumulation mode aerosol number & 0.002 & 0.043 & $\mathbf{0 . 1 9 8}$ \\
Cloud updraft velocity & $\mathbf{0 . 3 5 8}$ & $\mathbf{0 . 5 0 0}$ & $\mathbf{0 . 2 0 9}$ \\
Updraft velocity standard deviation & 0.067 & $\mathbf{0 . 3 8 3}$ & 0.066 \\
Cloud droplet number & 0.025 & $\mathbf{0 . 3 4 3}$ & 0.014 \\
Aerosol sulfate mass fraction & 0.036 & 0.014 \\
\hline
\end{tabular}

${ }^{a}$ The parcel model was used for computing cloud droplet number. Strongest correlations are shown in bold.

from the presence of very high aerosol concentrations at cloud base, but variations thereof. The observations support this hypothesis; $N_{d}$ error decreases as the plume ages and dilutes to the polluted (but homogeneous) background aerosol. Despite the correlation, the droplet number variability is still small compared to the highly variable aerosol near the vicinity of a power plant plume (Figure 4) for two reasons: droplet number variability is inherently less than the CCN variability [Sotiropoulou et al., 2006], and clouds may not respond to aerosol variations when they take place at small particle sizes and $s_{\max }$ is not sufficiently high to activate them. The latter can be seen in Figure 4; most of the aerosol variability is seen in small diameters $(<60 \mathrm{~nm})$, while droplets formed upon $\mathrm{CCN}$ with diameter greater than $70 \mathrm{~nm}$ (simulations suggest that $s_{\max } \sim 0.085 \%$ ). For nonpower-plant plume flights (IC9,10,11), cloud droplet error correlates with cloud droplet number (but not sulfate fraction or aerosol number), which suggests the presence of minor biases in the $N_{d}$ observations, which however are not significant enough to affect closure.

[26] Droplet number error also arises by assuming that aerosol chemical composition is invariant with particle size (section 3.3). Broekhuizen et al. [2005], Medina et al. [2007] and Sotiropoulou et al. [2006] have shown that this assumption for polluted areas can result in up to $50 \%$ error in CCN predictions. If our data set is subject to similar uncertainty, the resulting $N_{d}$ error should range between 10 and $25 \%$ [Sotiropoulou et al., 2006], well within the observational uncertainty. If organics partially dissolve and depress droplet surface tension, $N_{d}$ can become less sensitive to variations in chemical composition [Rissman et al., 2004].

[27] Figure 8 presents the sensitivity of droplet number prediction error, averaged over the data set, to the uptake coefficient, $a_{c}$. Figure 8 displays the $N_{d}$ standard deviation only for the parcel model, as the parameterization exhibits roughly the same behavior. The sensitivity analysis was done using the parcel model and activation parameterization, and assuming that the organic fraction is insoluble. Assuming that the droplet number prediction error is random, our simulations indicate that the "best fit" value of $a_{c}$ (i.e., the value which the average $N_{d}$ error is minimal and its standard deviation lies between the measured droplet uncertainty range) is 0.06 , which is in agreement with values obtained from the Conant et al. [2004] and Meskhidze et al. [2005] closure studies. Assuming a 20\% uncertainty in observed $N_{d}$ (and neglecting the $N_{d}$ error standard deviation) constrains $a_{c}$ between 0.03 and 1.0 (Figure 8). Peng et al. [2005] also obtain good closure using a much different $a_{c}(=1)$ in their analysis; this does not suggest that the closure is insensitive to $a_{c}$, but rather that updraft velocity and droplet number measurements require reduction in their uncertainty (Figure 8) to further constrain $a_{c}$.

[28] Finally, we assess the sensitivity of droplet closure to "chemical effects" (i.e., solubility of the organic fraction and depression of surface tension); the focus is to assess whether different values of the uptake coefficient and organic solubility (compared with the "base case" simulations for $a_{c}=0.06$ ) can yield good closure. In the sensitivity analysis, the dissolved organic was assumed to have a molar volume of $66 \mathrm{~cm}^{3} \mathrm{~mol}^{-1}$ and a Van't Hoff factor of 1 , which is consistent with a lower limit of properties derived from the activation of water-soluble organic carbon extracted from biomass burning samples (A. Asa-Awuku, Georgia Institute of Technology, personal communication, 2006). Organic solubility varied from $10^{-4}$ to $1 \mathrm{~kg} \mathrm{~kg}^{-1}$; when surface tension is allowed to decrease, we use the correlation of Facchini et al. [1999], assuming 8 mols of carbon per mol of dissolved organic [Nenes et al., 2002]. We also consider two values of the uptake coefficient, 0.06 and 1.0. Simulations indicate (Figure 9) that organic solubility less than $10^{-3} \mathrm{~kg} \mathrm{~kg}^{-1}$ is not enough to affect $\mathrm{CCN}$ (thus droplet number) concentrations. All the organic dissolves during activation when its solubility is larger than $10^{-2} \mathrm{~kg} \mathrm{~kg}^{-1}$; this leads to an average increase

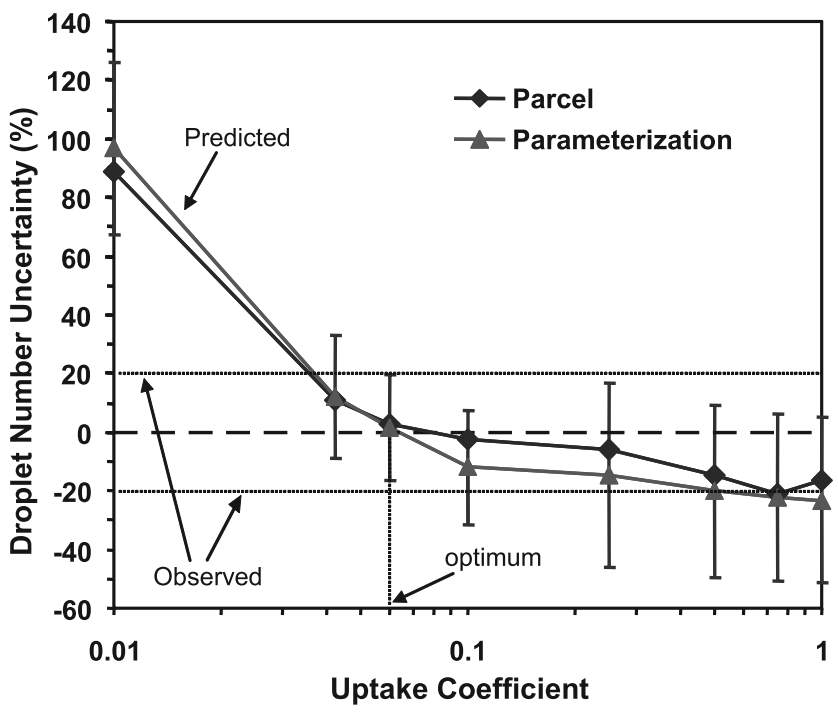

Figure 8. Sensitivity of droplet number error (between model and observations) to the value of the water vapor uptake coefficient. 


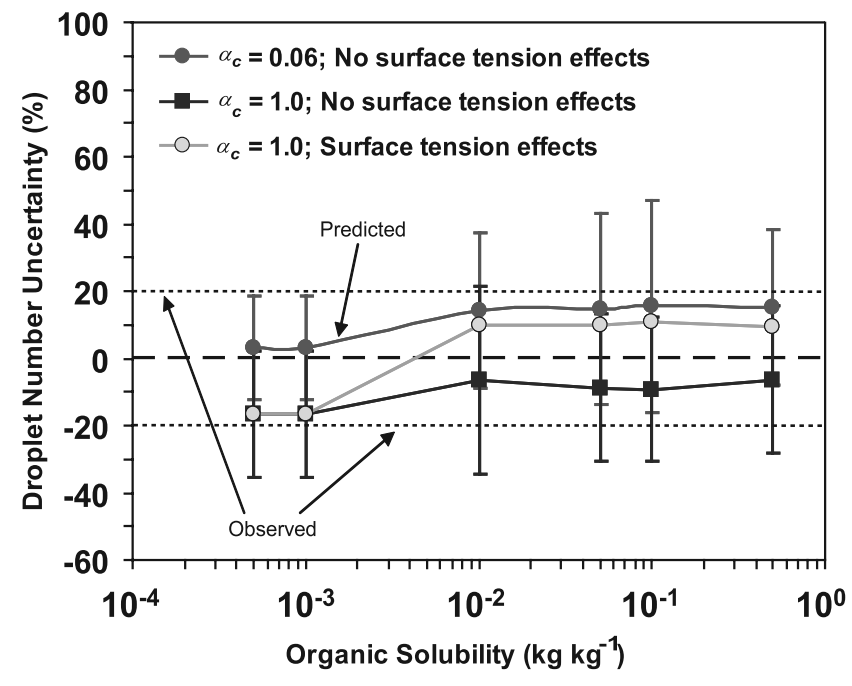

Figure 9. Sensitivity of droplet number error (between model and observations) to the solubility of the aerosol organic mass. The dissolved organic was assumed to have a molar volume of $66 \mathrm{~g} \mathrm{~mol}^{-1}$ and a Van’t Hoff factor of 1 .

in droplet number (error) by $10-15 \%$, accompanied with a substantial increase in droplet error variability. If surface tension depression is included, droplet number (error) is on average increased by about $30 \%$ compared to the "base case" simulation. Surface tension depression is considered only for simulations with $a_{c}=1.0$, as a lower value would yield droplet error outside of the uncertainty range. Using a larger organic molar volume (i.e., molecular weight) would just decrease their effect on CCN activation; a lower molar volume is unlikely, given that a lower estimate was already used. The simulations suggest that combinations of organic solubility, degree of surface tension depression and uptake coefficient can give cloud droplet closure within experimental uncertainty. However, the "base case" conditions give by far the best closure since average droplet error and its variability are within measurement uncertainty (Figure 9). This suggests that "chemical effects" do not considerably influence aerosol activation. The sensitivity analysis above illustrates the importance of reducing the droplet number measurement uncertainty. On the basis of Figure 9, a 10\% uncertainty would further constrain the extent of "chemical effects" on cloud droplet formation.

\section{Summary}

[29] This study analyzes 27 cumuliform and stratiform clouds sampled aboard the CIRPAS Twin Otter during the 2004 ICARTT (International Consortium for Atmospheric Research on Transport and Transformation). A unique feature of the data set is the sampling of highly polluted clouds within the vicinity of power plant plumes. In situ observations of aerosol size distribution, chemical composition and updraft velocity were input to (1) a detailed adiabatic cloud parcel model [Nenes et al., 2001, 2002] and (2) the modified NS parameterization [Fountoukis and Nenes, 2005; Nenes and Seinfeld, 2003]; predicted droplet number is then compared with the observations. Remark- able closure was achieved (on average to within 10\%) for parcel model and parameterization. The error in predicted cloud droplet concentration was found to correlate mostly with updraft velocity. Aerosol number also correlated with droplet error for clouds affected by power plant plumes (which is thought to stem from spatial variability of the aerosol not considered in the closure). Finally, we assess the sensitivity of droplet closure to "chemical effects." A number of important conclusions arise from this study:

[30] 1. Cloud droplet number closure is excellent even for the highly polluted clouds downwind of power plant plumes. Droplet number error does not correlate with background pollution level, only with updraft velocity and aerosol mixing state.

[31] 2. A highly variable aerosol does not necessarily imply a highly variable $N_{d}$ concentration. The clouds in this study often do not respond to aerosol variations because they take place primarily at small particle sizes, and cloud $s_{\max }$ is not high enough to activate them. Any droplet variability that does arise is inherently less than the CCN variability it originated from [Sotiropoulou et al., 2006].

[32] 3. Usage of average updraft velocity is appropriate for calculating cloud droplet number.

[33] 4. The water vapor uptake coefficient ranges between 0.03 and 1.0. Optimum closure (for which average $N_{d}$ error is minimal and its standard deviation is within droplet measurement uncertainty) is obtained when the water vapor uptake coefficient is about 0.06 . This agrees with values obtained from previous closure studies for polluted stratocumulus [Meskhidze et al., 2005] and marine cumulus clouds [Conant et al., 2004].

[34] 5. On average, organic species do not seem to influence activation through contribution of solute and surface tension depression. Optimal cloud droplet closure is obtained if the $\mathrm{CCN}$ are approximated by a combination of soluble inorganics and partially soluble organics (less than $1 \mathrm{~g} \mathrm{~kg}^{-1}$ water assuming a molar volume of $66 \mathrm{~cm}^{3} \mathrm{~mol}^{-1}$ and a Van't Hoff factor of 1).

[35] 6. The cloud droplet activation parameterization used in this study [Nenes and Seinfeld, 2003; Fountoukis and Nenes, 2005] has performed as well as the detailed cloud parcel model. Excellent performance has also been reported by Meskhidze et al. [2005]. Together, both studies suggest that the parameterization can robustly be used in GCM assessments of the aerosol indirect effect.

[36] 7. Distinguishing the "chemical effects" on the cloud droplet spectrum requires the observational uncertainty to be of order $10 \%$.

[37] The above conclusions can serve as much needed constraints for the parameterization of aerosol-cloud interactions in the North America. Future in situ studies will determine the robustness of our findings.

[38] Acknowledgments. We acknowledge the support of the National Science Foundation under award ATM-0340832. C.F., A.N. and N.M. acknowledge support from an NSF CAREER award, a NASA EOS-IDS and a NASA NIP. C.F. acknowledges support from a Gerondelis Foundation Fellowship.

\section{References}

Andreae, O. M., C. D. Jones, and P. M. Cox (2005), Strong present-day aerosol cooling implies a hot future, Nature, 435, 1187-1190. 
Asa-Awuku, A., and A. Nenes (2007), Effect of solute dissolution kinetics on cloud droplet formation: 1. Extended Köhler theory, J. Geophys. Res., doi:10.1029/2005JD006934, in press.

Bahreini, R., J. L. Jimenez, J. Wang, R. C. Flagan, J. H. Seinfeld, J. T. Jayne, and D. R. Worsnop (2003), Aircraft-based aerosol size and composition measurements during ACE-Asia using an Aerodyne aerosol mass spectrometer, J. Geophys. Res., 108(D23), 8645, doi:10.1029/2002JD003226.

Baumgardner, D., and M. Spowart (1990), Evaluation of the Forward Scattering Spectrometer Probe. Part III: Time response and laser inhomogeneity limitations, J. Atmos. Oceanic Technol., 7, 666-672.

Baumgardner, D., H. Jonsson, W. Dawson, D. O'Connor, and R. Newton (2001), Cloud, aerosol and precipitation spectrometer: A new instrument for cloud investigations, Atmos. Res., 59-60, 251-264.

Boucher, O., and U. Lohmann (1995), The sulfate-CCN-cloud albedo effect: A sensitivity study with two general circulation models, Tellus, Ser. B, 47, $281-300$.

Brasseur, G. P., and E. Roeckner (2005), Impact of improved air quality on the future evolution of climate, Geophys. Res. Lett., 32, L23704, doi:10.1029/2005GL023902.

Brenguier, J.-L. (1989), Coincidence and deadtime corrections for particle counters. Part II: High concentration measurements with an FSSP, J. Atmos. Oceanic Technol., 6, 575-584.

Brenguier, J.-L., T. Bourrianne, A. Coelho, J. Isbert, R. Peytavi, D. Trevarin, and P. Weschler (1998), Improvements of droplet size distribution measurements with the Fast-FSSP (Forward Scattering Spectrometer Probe), J. Atmos. Oceanic Technol., 15, 1077-1090.

Broekhuizen, K., R. Y.-W. Chang, W. R. Leaitch, S.-M. Li, and J. P. D. Abbatt (2005), Closure between measured and modeled cloud condensation nuclei $(\mathrm{CCN})$ using size-resolved aerosol compositions in downtown Toronto, Atmos. Chem. Phys. Disc., 5, 6263-6293.

Burnet, F., and J.-L. Brenguier (2002), Comparison between standard and modified forward scattering spectrometer probes during the small cumulus microphysics study, J. Atmos. Oceanic Technol., 19, 1516-1531.

Chuang, P. (2003), Measurement of the timescale of hygroscopic growth for atmospheric aerosols, J. Geophys. Res., 108(D9), 4282, doi:10.1029/ 2002JD002757.

Chuang, P. Y., D. R. Collins, H. Pawlowska, J. R. Snider, H. H. Jonsson, J. L. Brenguier, R. C. Flagan, and J. H. Seinfeld (2000), CCN measurements during ACE-2 and their relationship to cloud microphysical properties, Tellus, Ser. B, 52, 843-867.

Conant, W. C., et al. (2004), Aerosol-cloud drop concentration closure in warm cumulus, J. Geophys. Res., 109, D13204, doi:10.1029/2003JD004324.

Considine, G., and J. A. Curry (1998), Effects of entrainment and droplet sedimentation on the microphysical structure of stratus and stratocumulus clouds, Q. J. R. Meteorol. Soc., 124, 123-150.

Facchini, M., M. Mircea, S. Fuzzi, and R. Charlson (1999), Cloud albedo enhancement by surface-active organic solutes in growing droplets, Nature, $401,257-259$.

Feingold, G., and P. Y. Chuang (2002), Analysis of the influence of filmforming compounds on droplet growth: Implications for cloud microphysical processes and climate, J. Atmos. Sci., 59, 2006-2018.

Fountoukis, C., and A. Nenes (2005), Continued development of a cloud droplet formation parameterization for global climate models, J. Geophys. Res., 110, D11212, doi:10.1029/2004JD005591.

Ghan, S. J., R. Easter, E. Chapman, H. Abdul-Razzak, Y. Zhang, L. Leung, N. Laulainen, R. Saylor, and R. Zaveri (2001a), A physically-based estimate of radiative forcing by anthropogenic sulfate aerosol, J. Geophys. Res., 106, 5279-5293.

Ghan, S. J., N. Laulainen, R. Easter, R. Wagener, S. Nemesure, E. Chapman, Y. Zhang, and R. Leung (2001b), Evaluation of aerosol indirect forcing in MIRAGE, J. Geophys. Res., 106, 5317-5334.

Gultepe, I., and G. Isaac (1996), The relationship between cloud droplet and aerosol number concentrations for climate models, Int. J. Climatol., 16, $941-946$.

Hallberg, A., et al. (1997), Microphysics of clouds: Model versus measurements, Atmos. Environ., 31, 2453-2462.

Jaenicke, R., and T. Hanusch (1993), Simulation of the optical-particle counter forward scattering spectrometer probe-100 (FSSP-100)-Consequences for size distribution measurements, Aerosol Sci. Technol., 18(4), $309-322$.

Jayne, J. T., D. C. Leard, X. Zhang, P. Davidovits, K. A. Smith, C. E. Kolb, and D. Worsnop (2000), Development of an aerosol mass spectrometer for size and composition analysis of submicron particles, Aerosol Sci. Technol., 33, 49-70.

Jensen, J. B., and R. J. Charlson (1984), On the efficiency of nucleation scavenging, Tellus, Ser. B, 36, 367-375.

Jones, A., D. L. Roberts, and A. Slingo (1994), A climate model study of indirect radiative forcing by anthropogenic sulphate aerosols, Nature, $370,450-453$.
Khairoutdinov, M., D. Randall, and C. DeMott (2005), Simulations of the atmospheric general circulation using a cloud-resolving model as a superparameterization of physical processes, J. Atmos. Sci., 62(7), $2136-2154$

Kiehl, J. T., T. L. Schneider, P. J. Rasch, M. C. Barth, and J. Wong (2000), Radiative forcing due to sulfate aerosols from simulations with the NCAR Community Climate Model, J. Geophys. Res., 105, 14411457.

Laaksonen, A., T. Vesala, M. Kulmala, P. M. Winkler, and P. E. Wagner (2004), On cloud modeling and the mass accommodation coefficient of water, Atmos. Chem. Phys. Disc., 4, 7281-7290.

Lance, S., A. Nenes, and T. Rissman (2004), Chemical and dynamical effects on cloud droplet number: Implications for estimates of the aerosol indirect effect, J. Geophys. Res., 109, D22208, doi:10.1029/ 2004JD004596.

Li, Y. Q., P. Davidovits, Q. Shi, J. T. Jayne, and D. R. Warsnop (2001), Mass and thermal accommodation coefficients of $\mathrm{H}_{2} \mathrm{O}_{(\mathrm{g})}$ on liquid water as a function of temperature, J. Phys. Chem. A, 105, 10,62710,634 .

Lohmann, U., and J. Feichter (1997), Impact of sulfate aerosols on albedo and lifetime of clouds: A sensitivity study with the ECHAM4 GCM, J. Geophys. Res., 102, 13,685-13,700.

Lohmann, U., and J. Feichter (2004), Global indirect aerosol effects: A review, Atmos. Chem. Phys. Disc., 4, 7561-7614.

Lohmann, U., J. Feichter, C. C. Chuang, and J. E. Penner (1999), Predicting the number of cloud droplets in the ECHAM GCM, J. Geophys. Res. 104, 9169-9198.

Lohmann, U., J. Feichter, J. E. Penner, and R. Leaitch (2000), Indirect effect of sulfate and carbonaceous aerosols: A mechanistic treatment, J. Geophys. Res., 105, 12,193-12,206.

Medina, J., A. Nenes, R.-E. P. Sotiropoulou, L. D. Cottrell, L. D. Ziemba, P. J. Beckman, and R. J. Griffin (2007), Cloud condensation nuclei closure during the International Consortium for Atmospheric Research on Transport and Transformation 2004 campaign: Effects of size-resolved composition, J. Geophys. Res., 112, D10S31, doi:10.1029/2006JD007588.

Menon, S., A. D. DelGenio, D. Koch, and G. Tselioudis (2002), GCM simulations of the aerosol indirect effect: Sensitivity to cloud parameterization and aerosol burden, J. Atmos. Sci., 59, 692-713.

Meskhidze, N., A. Nenes, W. C. Conant, and J. H. Seinfeld (2005), Evaluation of a new cloud droplet activation parameterization with in situ data from CRYSTAL-FACE and CSTRIPE, J. Geophys. Res., 110, D16202, doi:10.1029/2004JD005703.

Nenes, A., and J. H. Seinfeld (2003), Parameterization of cloud droplet formation in global climate models, J. Geophys. Res., 108(D14), 4415, doi:10.1029/2002JD002911.

Nenes, A., S. Ghan, H. Abdul-Razzak, P. Chuang, and J. Seinfeld (2001), Kinetic limitations on cloud droplet formation and impact on cloud albedo, Tellus, Ser. B, 53, 133-149.

Nenes, A., R. J. Charlson, M. C. Facchini, M. Kulmala, A. Laaksonen, and J. H. Seinfeld (2002), Can chemical effects on cloud droplet number rival the first indirect effect?, Geophys. Res. Lett., 29(17), 1848, doi:10.1029/ 2002GL015295.

Peng, Y., U. Lohmann, R. Leaitch, C. Banic, and M. Couture (2002), The cloud albedo-cloud droplet effective radius relationship for clean and polluted clouds from RACE and FIRE.ACE, J. Geophys. Res., 107(D11), 4106, doi:10.1029/2000JD000281.

Peng, Y., U. Lohmann, and R. Leaitch (2005), Importance of vertical velocity variations in the cloud droplet nucleation process of marine stratus clouds, J. Geophys. Res., 110, D21213, doi:10.1029/2004JD004922.

Pruppacher, H. R., and J. D. Klett (2000), Microphysics of Clouds and Precipitation, Springer, New York.

Randall, D., M. Khairoutdinov, A. Arakawa, and W. Grabowski (2003), Breaking the cloud parameterization deadlock, Bull. Am. Meteorol. Soc., 84(11), 1547-1564.

Rissman, T., A. Nenes, and J. H. Seinfeld (2004), Chemical amplification (or dampening) of the Twomey effect: Conditions derived from droplet activation theory, J. Atmos. Sci., 61(8), 919-930.

Rotstayn, L. D., and J. E. Penner (2001), Indirect aerosol forcing, quasiforcing, climate response, J. Clim., 14, 2960-2975.

Shaw, R. A., and D. Lamb (1999), Experimental determination of the thermal accommodation and condensation coefficients of water, J. Chem Phys., 111, 10,659-10,663.

Shulman, M. L., M. C. Jacobson, R. J. Charlson, R. E. Synovec, and T. E. Young (1996), Dissolution behavior and surface tension effects of organic compounds in nucleating cloud droplets, Geophys. Res. Lett., 23, $277-$ 280.

Snider, J. R., and J. L. Brenguier (2000), Cloud condensation nuclei and cloud droplet measurements during ACE-2, Tellus, Ser. B, 52, $827-$ 841 . 
Snider, J. R., S. Guibert, J.-L. Brenguier, and J.-P. Putaud (2003), Aerosol activation in marine stratocumulus clouds: 2. Köhler and parcel theory closure studies, J. Geophys. Res., 108(D15), 8629, doi:10.1029/ 2002JD002692.

Sorooshian, A., F. J. Brechtel, Y. Ma, R. J. Weber, A. Corless, R. C. Flagan, and J. H. Seinfeld (2006a), Modeling and characterization of a particleinto-liquid sampler (PILS), Aerosol Sci. Technol., 40, 396-409.

Sorooshian, A., et al. (2006b), Oxalic acid in clear and cloudy atmospheres: Analysis of data from International Consortium for Atmospheric Research on Transport and Transformation 2004, J. Geophys. Res., 111, D23S45, doi:10.1029/2005JD006880.

Sotiropoulou, R. E. P., J. Medina, and A. Nenes (2006), CCN predictions: Is theory sufficient for assessments of the indirect effect?, Geophys. Res. Lett., 33, L05816, doi:10.1029/2005GL025148.

Turpin, B. J., and H. Lim (2001), Species contributions to PM2.5 mass concentrations: Revisiting common assumptions for estimating organic mass, Aerosol Sci. Technol., 35, 602-610.
Wang, J., R. C. Flagan, and J. H. Seinfeld (2003), A differential mobility analyzer (DMA) system for submicron aerosol measurements at ambient relative humidity, Aerosol Sci. Technol., 37, 46-52.

R. Bahreini, NOAA, Boulder, CO 80305, USA.

F. Brechtel, R. C. Flagan, and J. H. Seinfeld, Environmental Science and Engineering, California Institute of Technology, Pasadena, CA 91125, USA.

W. C. Conant, Department of Atmospheric Sciences, University of Arizona, Tucson, AZ 85721, USA.

C. Fountoukis and A. Nenes, School of Chemical and Biomolecular Engineering, Georgia Institute of Technology, Atlanta, GA 30332, USA. (nenes@eas.gatech.edu)

H. Jonsson, Center for Interdisciplinary Remotely-Piloted Aircraft Studies, Naval Postgraduate School, Monterey, CA 93933, USA.

N. Meskhidze, School of Marine, Earth, and Atmospheric Sciences, North Carolina State University, Raleigh, NC 27695, USA.

S. Murphy, A. Sorooshian, and V. Varutbangkul, Department of Chemical Engineering, California Institute of Technology, Pasadena, CA 91125, USA. 